International Journal of Database Management Systems ( IJDMS ) Vol.6, No.3, June 2014

\title{
PROPOSED RANKING FOR POINT OF SALES USING DATA MINING FOR TELECOM OPERATORS
}

\author{
Ayman Alawin and Mohammad Al-ma'aitah \\ Al-Balqa' Applied University, Jordan
}

\begin{abstract}
This study helps telecom companies in making decisions that optimize its sales points to reduce costs, also to identify profitable customers and churn ones. This study builds two research models; physical model for continuous mining of database where ever it resides i.e., as we have On Line Analytic Processing (OLAP) we must have On Line Data Mining (OLDM), and logical model using Technology Acceptance Model. Previous Studies showed that using basic information of customers, call details and customer service related data, a model can effectively achieve accurate prediction data.

This research gives a new definition and classification for telecommunication services from the data mining point of view. Then this research proposed a formula for total rank a shop and each term of this formula gives a sub rank. The proposed example shows that even a shop with lower numbers of population and visitors, it still has higher rank.

This research suggested that telecom operators has to concentrate more on their e-shopping and epayment as it is more cost effective and use data from shops for marketing issues. Some assumptions made in this study need to be validated using surveys, also proposed ranking should be applied on live database.
\end{abstract}

\section{KEYWORDS}

Data Mining, Telecommunication, TAM, CRM.

\section{INTRODUCTION}

\subsection{BACKGROUND}

Direct marketers can deliver more effective campaigns by using location based information that contains a reference to a person or physical place such as city or street. This information translates into valuable data about customers, potential customers, and placement of store locations [1].

As companies build relationships with their customers through a variety of transactions (e.g., service requests, service complaint), they collect large amounts of data. When combined with demographic attributes, this information can be used to maximize return on marketing campaigns: identify most likely buyers of new services; and identify valuable customers and their needs [2]. 
International Journal of Database Management Systems ( IJDMS ) Vol.6, No.3, June 2014

The goal of data mining is to extract knowledge from a large data set in an understandable structure which can be used to obtain more accurate prediction results. The decision of using data mining techniques in this study was based on the fact that telecommunication companies collect a large amount of data relating to different aspects of the interaction that takes place between the company and its customers and this is why telecommunications industry was first to adopt data mining technology [3]. The amount of data is so huge such that manual analysis of the data is difficult, even impossible [4]. While in most cases scattered, these data when mined may contain valuable information relating to the prediction problem. Examples of such data are: (a) customer profiles, (b) usage of the offered service, and (c) financial transactions between the customers and the company, (d) queuing system that is responsible for scheduling serving customers in any of their shops, (e) one or more call center for on-line customer service requests or for service complaints.

\subsection{PROBLEM STATEMENT AND OBJECTIVES}

Customers of telecom operator have two main ways to communicate with the operator; one is through call centers mainly for mobile customers, and the other one is face to face through the nearest shop to the customers. The reasons for establishing a new shop in any area can be: Increased revenue by touching new customers, more customer satisfaction and loyalty, and advertisement for its services. The disadvantages of opening a new shop are the costs associated with staff and logistic, and also the difficulty in assessing the added value of this new shop, i.e., whether it has achieved the target or not. The same thing applies to the current existing shops.

Usually, operators ranks their shops and spend more money in terms of staff and logistic for the most important shops from their point of view. Interviews showed that the ranking is based on the population, total number of visitors, financial outcome, and Stuff count. The number of ranks currently used is fixed to a predefined number of levels, usually three.

The assessment of shops performance at the end of a certain period - usually a month- is based only on tangible outcomes of these shops, i.e., achieving the sales targets which were set manually for each employee by sales management after adding a percent to the average of last months. These objectives are fixed for the whole month. Also telecom operators motivate their front desk staff according to the number of services sold. This criterion is somehow weak for the following reasons:

Sales objectives are subjective to sales management judgment.

Objectives may be achieved much earlier if employee is located in an area of strong buyers.

It doesn't measure intangible services like information or declaration requests by the customer.

It doesn't motivate employees such as cashiers, and omits many other activities of the shop.

Cross selling, deep selling and up selling measurements are another problems facing telecom companies, the employees of these companies are currently manually use some kind of external application like "matter code" to register a cross selling activity [10].

This study intended to achieve the following objectives: 
International Journal of Database Management Systems ( IJDMS ) Vol.6, No.3, June 2014

To discuss TAM model and use it as a model for data mining.

Defining telecom services and classifying them from a data mining perspective.

Put new criteria to rank telecom point of sales.

Propose new usages of data mining

Ranking points of sales is a new way in studying the market, this study helps companies in making decisions that optimize its sales points to reduce costs, also to identify profitable customers and churn ones to maximize market share. Most researches in customer profiling within the telecom industry use the call data records as the main database to mine, but omit service usage by customers. This research proposes other sources of data to classify customers, classify shop centers, and churn prediction, i.e., any information about the customer in any database should be used in order to have complete view about customer.

\subsection{RESEARCH MODEL}

\subsubsection{Physical Model}

All data mining researches that predict churn customers or segment them in telecom use Data Warehouses (DW) as the physical source for data in building a model [5] [6] [7] [8] [9] [11] [12], this is due to the assumption that the needed data is always residing in the DW. This assumption is not always valid as telecom operators have a huge amount of data and changing frequently which cannot be stored at DW; for cost reasons, security reasons, and non importance of data. DW used in telecom companies contains three types of databases; call data records made by subscribers, call data records of interconnection between the carrier and other operators, and information on products and services from customers [12]. Our model overcomes this trend because most telecom equipment and information systems have their own storage for their logs, enabling mining the database where ever it resides. We will call these Temporary Data Stores as TDS, because usually they are overwritten after a specific period of time according to equipment specification. Figure 1 below shows the physical model of the research, the sources of data are DW and TDS. Both of data sources must be fetched to extract data into a temporary DW to start mining it. The benefit from this model is that it allows for continuous mining of the data since TDS contains volatile data.



Figure 1: Data Mining Physical Model (Conceptualized by the researcher) 
International Journal of Database Management Systems ( IJDMS ) Vol.6, No.3, June 2014

\subsubsection{Logical Model: DM and Technology Acceptance Model (TAM)}

For logical model, the TAM model was used, as both DM and TAM are tools to predict future. TAM, developed by Davis in 1989 and modified in 1996 (Fig.2). The primary purpose of the TAM is to predict IS/IT acceptance and diagnose design problems before users actually use new systems. Therefore, the TAM has been widely used for the purpose of predicting, explaining and increasing the understanding of user acceptance of information systems [13]. The TAM model suggests that when users encounter a new technology, two variables affect when and how they will use the system; Perceived Usefulness (PU) and Perceived Ease Of Use (PEOU). PU is the degree to which a user believes that using a particular system would enhance the performance of job. PEOU is the degree to which a user believes that using a particular system would easy. The TAM proposes that PU and PEOU affect users' attitude towards using information systems. This attitude affects the Behavioral Intention (BI) to use, which, in turn, will determine usage of the system. PEOU has a mediating effect on PU, and BI is influenced by external variables through PU and PEOU [14].



Figure 2: TAM model

Many researchers tried to add more factors that may affect the acceptance to technology, but all of them somehow fall under the perceived usefulness factor; because this is a broad statement acting as an umbrella that include all expectations other than the PU and PEOU. Also all of them used questionnaire over and over to prove that the usefulness and ease of use are motivators to accept new technology, this study doesn't underestimates the importance of questionnaire but it assumes that it is not enough to predicts acceptance.

This research modifies the TAM model from the Data mining prospective. Firstly by replacing the word "system" by "service", so that the last stage of the TAM model becomes "Actual current service usage". This is for two reasons; first because what is requested by any technology is to deliver a service to some user, and secondly, we may have a system that delivers more than one service, one or more are accepted while the others are not accepted in usage. The second modification will be by replacing the word Behavioral Intention to Business Intelligence which is also abbreviated as BI, and with BI we mean using analytic methods or data mining, which is one of main business intelligence tools that can study current and previous usage to predict the future. The BI block is the physical model explained previously. For the input to BI to be complete, external variables must be included. The third modification will be using the TAM model but in reverse direction as in the figure 3 below, the idea comes from the assumption that there is no service appears from scratch, and anything in the world has a precedent, and by studying this precedent we can forecast future. Attitude toward using the new service and the intention to use will be merged assuming that attitude will always lead to intention, and this should be the end of the prediction. We will call this model Subscriber Acceptance Model (SAM). 


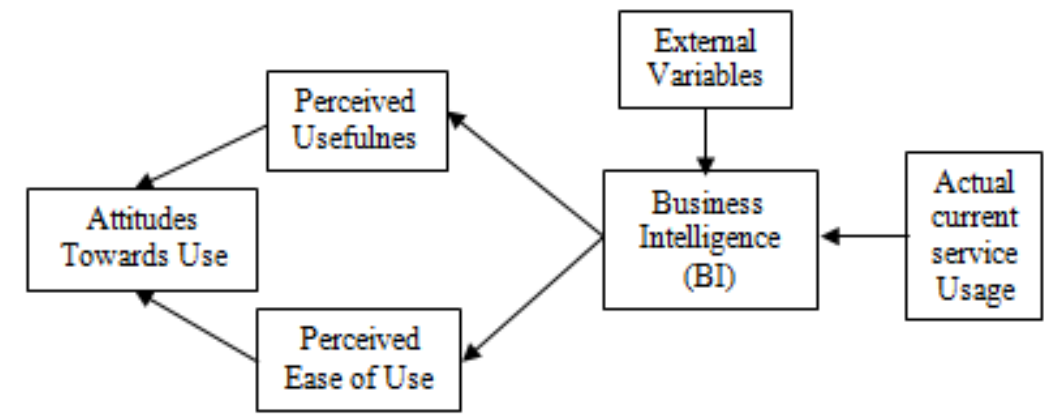

Figure 3: Logical Model: Subscriber Acceptance Model (Conceptualized by the researchers)

\subsection{RESEARCH METHODOLOGY}

The research methodology used to conduct the research is a qualitative methodology depending on observations and descriptions. It is subjectively and descriptive, researchers used their opinion, knowledge and experience. The study design involves using interviews with shops managers. and observation. This research reports on a case study of the Jordanian Telecom companies, which are a multi service operators, fixed, mobile, and Wi-max.

\subsection{RELATED WORK}

According to [1], the best practice direct marketers can employ is to consider adding locationbased data to their campaign analytics. That's because approximately $80 \%$ of all business decisions are tied to location. So, obtaining a clear view of a campaign target area through street maps or postal address provides a deeper view of customers and potential customers. And, at the same time, direct marketers can also gather more intelligence about customers for future campaigns by viewing information about those customers on a physical map. This data works with all distribution methods, including direct mail, social media and other online marketing tactics. The ultimate impact of using location-based data effectively is more sound business decisions and an increase in operational efficiency.

Authors of [7] focused on churn analysis in telecom sector, were their objectives were to find out which types of customers of a telecommunications company are likely to churn, and when. They assure that statistical methods are not suitable for churn prediction, because statistical approaches are limited in capacity and scope. In response to this fact, data mining techniques are becoming widely used to provide proven decision support system based on advanced techniques. They focused only on postpaid phones with respect to churn prediction, the attributes used in their database were wither payment was within the allowed period, and duration of calls made by customer. The decision was that the customer is churn/not churn.

Authors of [8] used data exploration technology to build a predictive model to find out the possible churners. They compared the performance of different data mining techniques to select appropriate data mining tools. They used whether payment was within the allowed period and added other variables such as bill amount and whether the phone was suspended previously, and the demographic information about customers like gender and age. They found that only decision tree and neural network techniques can create a robust model for prediction. Authors of [11] found that decision tree model surpasses the neural network model in the prediction of churn. 
International Journal of Database Management Systems ( IJDMS ) Vol.6, No.3, June 2014

Evaluation shows that using basic information of location, call details and customer service related data, the model can effectively achieve accurate prediction data. Also it was noted that all researches about data mining in telecom sector study customers separately as prepaid or postpaid.

\section{LITERATURE REVIEW}

\subsection{Relationship Marketing and Customer Relation Management}

Relationship Marketing appeared as a new concept in the 1980s, as a result of the shift in focusing from customer acquisition to customer retention as an approach to create, maintain, and enhance long-term associations with customers and other stakeholders [15]. Another definition that introduced the role of the IT define relationship marketing as a "process where the main activities are to create a database including existing and potential customers, to approach these customers using differentiated and customer-specific information about them, and to evaluate the life-term value of every single customer relationship and the costs of creating and maintaining them." [16].

To apply relationship marketing, firm must identify the customers it wants to enhance its relationship with them, classify them according to their needs, interact with those customers, and then customize product and services for each customer. This process requires information flow process, as well as technology and data repositories of customer data, which is the role of Customer Relationship Management (CRM) through communications in order to improve customer's acquisition, retention, and loyalty [15]. CRM technologies are the tools that enable business to leverage information from their databases; to get and give the right information to or from the right person at the right time. Some of CRM parts are [17]:

- Operational CRM: It includes daily communication with clients. Customer data is collected through a whole range of touch points such as, contact centre, point of sales, mail, fax, sales force, web, etc. The data then are stored in a centralized customer database. This system gives employees direct access to important information about the customer.

- Analytical CRM: It means the collection, storage, extraction, processing, reporting, and interpreting customer data, i.e., using Online Analytical Processing (OLAP).

\subsection{Data Mining in Telecommunication Industry}

According to [7], telecommunication sector data mining can be used in prediction of customers at risk of leaving the company (churners), prediction of customers who will refuse to pay their bills (insolvency), and to identify fraudulent users.

Recent researches like [3] and [14] had summarized all data mining applications and business problems addressed as follows:

1. Marketing \& CRM: "Measure customer value and retain profitable customers, generate customer profiles and mine these for marketing purposes, acquire new customers, and chum analysis which includes chum prediction and chum management". 
International Journal of Database Management Systems ( IJDMS ) Vol.6, No.3, June 2014

2. Fraud Detection: "Identification of fraudulent users, detection of fraudulent entry to customer accounts, and discovery of unusual patterns like busy hour, switch \& route congestion patterns".

3. Network Management: "Identifications and predication of network faults, management of systems workload and resource utilization".

Data mining builds models to identify patterns among the attributes of objects, pattern is a mathematical (numeric and/or symbolic) relationship among data items. There are many types of patterns, but we are interested in two of them; cluster (segmentation) pattern which identifies natural groupings of things according to their known characteristics, such as assigning customers in different segments based on their demographics. The second pattern is prediction, which tells the nature of future occurrences of certain events based on what has happened in the past [5].

Most data mining techniques learn by example. The neural network or decision tree generator is fed thousands of training examples. After seeing enough of these examples, the tool comes up with a model in the form of a computer program that reads in unclassified records and updates each with a response rank [5]. An important issue is that the raw data is often not suitable for data mining. Before this data can be mined, features must be identified and then the data must be summarized using these features. Also, most data reside in the database of the equipment itself and not in separate databases for processing.

\section{NEW USED DATA}

Shops or points of sales are a mean for marketing employees to sell services to customers, while doing this task; the three entities (customers, services, and shop with its employees) provide a huge amount of data that may be used to achieve business goals. This chapter studies data of each entity.

\subsection{Shops Data}

It is a narrow vision of the operator to evaluate an area according to its social or political value and it is narrower to assess the performance according to ROI only. Companies searching to minimize cost and maximize customer satisfaction should take into its consideration the following information (attributes) of the object (shop):

1. The average population of the area, or its visitors if the area is a transit area, e.g., airport, university, mall, Commercial Street, etc.

2. Number of customers visiting the shop.

3. Number of customers buying a new service including paying bills.

4. Number of customers having a difficulty in one of the services or having information request.

5. Number of "no show" customers.

6. Average duration (slack time) of customer waiting time since arrival moment.

7. Payment methods used by customers of this shop.

8. Average of complaints received by call centers from this area.

9. Shops that are mostly used by each customer. 
International Journal of Database Management Systems ( IJDMS ) Vol.6, No.3, June 2014

Number of customers visiting a shop proportional to the population is one of main indicators of the importance of the shop. This figure contains all visitors to the shop regardless of buying a service or not and gives an idea of penetration of the company into this area.

Number of customers asking for a service is the second important variable of shop importance; it gives an indication of the acceptance and response of people to company services.

Not all visitors to a shop are asking for a service, some customers only need information about a service, or complaining. This figure cannot be documented as it is a verbal communication and the customer may be undefined. This is why it is categorized as "others" in the observed companies.

"No shown" customers are those who logged into the queuing system but didn't show when their turn to be served has come, this figure is due to customer leaving after long waiting time or logged into queuing system more than one time, both attitudes indicate unsatisfactory of customers.

Cash, credit cards, checks, bank transfers, mobile payments, and company web site are different used payment methods. Payment methods differ from individual to another, but sometimes it may be common for an area to prefer using one method over others. This research will look to these methods from the company point of view not from customer side, so it is normal that companies prefer on time payments and encourage using their own ways of payments like mobile payments or using on line e-commerce [20].

Average duration (slack time) is the average waiting time a customer has to wait till the clerk can serve him; this figure should be compared to the accepted waiting time.

The average number of complaints received by call centers that are related to service degradation in a particular shop area gives an idea about quality of the service in this area. Using this figure makes a new trend which is technical orientation of marketing team.

The last parameter is the group of shops that each customer visits for his service requests.

\subsection{Data Mining and Service Management:}

This section gives a new definition and classification for telecommunication services from the data mining point of view, this classification to be used later in database schema design.

The definition of services differs in a wide range. The following lists two different definitions and specifications for the notion of services in telecommunications industry;

- "Basic telecommunication service" is a term that is used as a common reference to both bearer services and teleservices, where bearer service is a type of telecommunication service that provides the capability to transmit signals between access points [23].

- Multimedia services combine two or more media components (e.g., voice, audio, data, video, pictures) within one call. A multimedia service may involve several parties and connections (different parties may provide different media components) and therefore flexibility is required in order to add and delete both resources and parties [22]. 
International Journal of Database Management Systems ( IJDMS ) Vol.6, No.3, June 2014

The listed definitions above demonstrate that there are different general meanings to services. This research defines a telecom service as any activity made by the customer and the information about this activity can be stored in a database. This stored information can be used to give an idea about the service usage. A declaration example of this definition is downloading a game from a mobile application store is a telecom service, but playing the game is service offered by the handset.

Services are created to add value, i.e., to increase the importance by making a difference. After a difference is made, importance may be not perceived the same by all customers. The wanted service should be acceptable, otherwise it is meaningless. The role of data mining is to decide acceptors.

There are many classifications for telecom services; it is classified from technology or customer points of views [18]; Multimedia services are typically classified as interactive (conversational, messaging and retrieval services) or distributed services (broadcast services) [22], or classified according to the media (bearer) characteristics (based on service classes specified by ITU-T [21]. Another classification by [23] was into teleservices and supplementary services. A teleservice provides the complete capability including terminal equipment functions for communication between users according to standard protocols and transmission capabilities between operators. A supplementary service is a service which modifies the basic teleservices.

This research adds new service classification method which is data mining point of view;

1. Some services are available for all mobile customers, running all the time, and don't add any information about the customer as he cannot control service usage, e.g., Calling Line Identification (CLI). This service is running all the time, while other services even available for all customers like Short Message Service (SMS) and Multimedia Service (MMS) but may be used or not used and it can be measured by its usage per day or per month.

2. Some supplementary services are replaced totally by handsets capabilities like abbreviated dialing or wakeup call. Also tracing the usage of these services is not possible because it is registered only at the core network data that is not accessed by external database.

3. Some services are controllable by the customer but it cannot be easily tracked if used or not, like call waiting service when a customer can receive two simultaneous calls.

4. Some services are not added to customer profile, e.g., roaming service is not recorded anywhere except during roaming and only for two weeks after coming back to home country in the Visitor Location Register (VLR) of the mobile core network [19].

5. Some services can be upgraded or downgraded like internet speed for ADSL or 3G.

6. Postpaid or prepaid should be treated as services, not as a type or category of the line, as long as the customer can change his profile from one to another.

7. Caller Line Identification Restriction (CLIR) is a special supplementary service, which its usage can be used to predict churn customers.

The listed classification above demonstrates that there are different types of services. This research concentrated on residential customers so it ignores services targeting enterprises like leased lines, Basic ISDN, and Primary ISDN in fixed networks, also closed user group and blackberry services in mobile networks. 
International Journal of Database Management Systems ( IJDMS ) Vol.6, No.3, June 2014

\subsection{Data Types and Sources:}

According to [4], telecom data include (a) call detail data or records, which describe the calls that traverse the telecommunication networks. Even though these data will not be used by this study in the same manner other studies did based on our assumption that new applications which uses Voice over Internet Protocol (VoIP) had changed the pattern a customer uses his telephone to make voice calls. (b) Network data, which describes the state of the hardware and software components in the network, also this study will not use this data but uses its impact when customer complaining about the service, and (c) Customer data, which describes the telecommunication customers.

This research adds another type of data which is shop data, and modifies the customer data to include services usage by customer. All data mentioned in the beginning of this chapter are available in the distributed databases of telecom companies; data source includes customer demography available at billing systems, call centers, and customer services system, queuing systems which are also called customer flow management systems. The only external information is the population of an area. Companies currently have two sources to get the population figure; (a) by using published statistics, (b) number of fixed lines used in that area.

One of the limitations found in the systems used in the observed operators is that there is no link between the queuing system and CRM, i.e., it wasn't possible to figure serving time according to service or customer.

\subsection{Preparing Database Tables (data extraction):}

\subsubsection{Customer tables}

These tables are extracted from billing information system which usually contains customer demographic information about the customer like name, address, contact phone, gender, and customer code or identification number. We are interested in the part of the attributes that helps in our research, e.g., name and national number will not add any value to any analysis.

Table (1): Customer (Tel_No, C_Id)

Where:

- $\quad$ C_Id is the customer Identification.

- Tel_No is the telephone number. The primary key for this table is Tel_No as it shouldn't be null and it should be unique.

\subsubsection{Services tables:}

These tables link customers to services through telephone number. If services were added to the previous table then we may have a lot of empty fields as some customers may have one service while others may have many of them which is not recommended for database schema design. So the service attribute should be treated as a separate entity. According to section 4, this research recommends using different table formats according to each service attributes. This research will choose a sample of each service type described previously.

Table (2) Roaming Service (Tel_No, Roam_date, Can_Date, Country, Operator) 
International Journal of Database Management Systems ( IJDMS ) Vol.6, No.3, June 2014

Where:

- $\quad$ Roam_date is the date the customer started roaming in another country

- Can_date is the date of coming to home country.

- Country is the visited country.

- Operator is the operator that customer chosen as a roaming partner in the visited country.

The primary key of this table is Tel_No and Roam_Date.

Table (3): CLIR (Tel_No., Date, \%usage)

Where:

\%usage is the percentage of calls using CLIR service, and Primary Key is Tel_No and Date

Tables (4): SMS or MMS (Tel_No, Date, Usage)

Where:

Usage is an integer showing how many MMS's were sent by this telephone number or how many Mega Bytes (MB) were downloaded by this customer.

Table (5): ADSL or WiMax or 3G upgrades (Tel_No, Date)

Where:

Date is the upgrade date.

Table (6): Complaints (Tel_No, Date, Service_ID, Res_Dur, Area)

Where:

- Service_ID is the service identification

- Res_Dur is the duration of resolving the complaint.

- Area is the location of service degradation

The primary key in this table is the telephone number and complaint date.

\subsubsection{Shop tables:}

Table (7): Shop (Shop_ID, Area, Pop)

Where:

- Shop_ID is the shop Identification, used as primary key is, because it is unique

- Area is the shop served area.

- Pop is the estimated population of the area served by this shop.

Table (8) Shop_employees: (Shop_ID, Emp_ID)

Where:

- Emp_ID is the Employee identification number

Table (9) Shop_Services: (Shop_ID, Service_ID, Tel_No, Date, Pay_method, Emp_ID) 
International Journal of Database Management Systems ( IJDMS ) Vol.6, No.3, June 2014

Where:

- Service_ID is the Service Identification.

- Pay_method is the payment method.

Table (10): Queue (Shop_ID, Service_ID, Date, Wait, No_Shown, Emp_ID)

Where:

- Wait is the time a customer wait till been served.

- No_Shown is the number of no shown customers.

\subsection{Proposed Ranking Formula}

To calculate the rank of a shop, all above parameters of section 4.3 can be figured by simple queries to the database. This research proposes the following formula to rank a shop:

Rank $=\frac{C_{V}}{C_{P}}+\frac{C_{S}}{C_{V}}+\frac{\left(T_{a}-T_{r}\right)}{T_{a}}+\frac{\left(C_{V}-C_{n}\right)}{C_{V}}+\frac{\left(C_{P}-C_{C}\right)}{C_{P}}+\frac{\left(C_{V}-C_{m}\right)}{C_{V}}+\frac{\left(3 P_{e}+2 P_{C}+P_{S}\right)}{P_{T}}$

Where:

$C_{V}$ : Number of Visitors (table 10) $\quad C_{P}$ : Population (table 7)

$C_{S}$ : Number of customers buying services (table 9)

$C_{n}$ : Number of customers not shown (table 10)

$C_{C}$ : Number of customers complaints (table 6)

$T_{a}$ : Accepted waiting time (Table 10) $\quad T_{r}$ : Real waiting time (table 10)

$C_{M}$ : Number of customers visiting other shops (multi shops visitors) (Table 10)

$P_{T}$ : Total number of payments (table 9) $P_{e}$ : Total number of electronic payments (table 9)

$P_{C}$ : Total number of cash and credit cards payments (table 9)

$P_{S}$ : Total number of payments with settlement (table 9)

Declaration Example:

\begin{tabular}{|c|c|c|c|c|c|c|c|c|c|c|c|c|}
\hline$C_{V}$ & $C_{P}$ & $C_{S}$ & $T_{a}$ & $T_{r}$ & $C_{n}$ & $C_{C}$ & $C_{M}$ & $P_{T}$ & $P_{e}$ & $P_{C}$ & $P_{S}$ & Rank \\
\hline 1000 & 10000 & 800 & 15 & 20 & 50 & 1200 & 200 & 60 & 10 & 30 & 20 & 5.03 \\
\hline 1500 & 20000 & 1300 & 15 & 25 & 80 & 1400 & 300 & 90 & 15 & 45 & 30 & 4.785 \\
\hline
\end{tabular}

The proposed example shows that even a shop with lower numbers of population and visitors it still has higher rank. 
International Journal of Database Management Systems ( IJDMS ) Vol.6, No.3, June 2014

\section{DISCUSSION}

From the previous section, a total rank was calculated for each shop. Describing each term in order of the ranking formula gives a sub rank;

Number of visitors out of the population to the shop gives an idea of penetration of the company into this area as mentioned before, if this figure is low means that customers at this area are not interested in new services and that marketing must start studying why this is happening.

The percentage of customers buying a new service out of all visitors gives an idea of customer acceptance to company's telecom services which we will use in next section to apply "subscriber acceptance model"

If the average waiting time is above a predefined threshold then this is an indication of bad quality of the service offered by shop team, this figure may lower the rank of the shop. This figure may be due to overloaded front office employees or unqualified. Comparing waiting time to other shops can help in deciding needed stuff and incentive. The acceptable waiting time is the time with minimum so shown.

If the number of complaints is above a predefined threshold then this is a bad indication of the quality of the service in this area, and that customers are probable churners. Shop stuff should be aware of this, and must master the necessary technical knowledge to use it when selling a service. Imagine how helpful to retain customers if an information system can pops up the complaints history for a customer while the employee is cancelling a service.

If most of the population is using other shops beside the one designed to serve them, then the rank of this shop is minimized. This may be helpful if the company wants to minimize the cost by closing a shop or staff reduction.

The ranking of payment methods for each area can be helpful in many ways, e.g., adding a credit machine if customers prefer using it, motivating cashiers if more customers are paying cash or more motivation if using company e-payment ways. This is why more weight was given to epayment over cash and settlement.

In mining network data it was possible to predict busy hour of the telecom core equipment, also mining waiting time and entrance to queuing system can predict shop busy hour of the day which can optimize stuff performance.

Using data mining to cluster services according to shop area is an indication for the marketing team about strong and weak points of market in this shop area, and predict the most targeted areas for new campaign and surveys (e.g., finding that a new generation for mobile services is at the lowest level of ranking in one of the commercial sites of the country). Also clustering customers according to services they use is another way to find the most targeted customers for new campaign, and Perceived Usefulness (PU).

Using data mining to cluster shops and customer according to complaints helps firms in predicting most targeted areas for awareness campaign and satisfaction surveys. Also indicates the Perceived Ease of Use (PEOU). 
International Journal of Database Management Systems ( IJDMS ) Vol.6, No.3, June 2014

Analyzing data can be used to measure cross selling by checking if more than one service was sold to the same customer by the same employee, and also for the whole shop if percentage of non service activities is minimized. Analyzing upgrade tables and switching from prepaid to postpaid measures up selling. Analyzing services usage tables measures deep selling.

Mining usage of CLIR service along with complaints, service downgrades, using roaming service, payment method, and changing to prepaid can predict churn customers.

\section{CONCLUSION AND FUTURE WORK}

\section{Conclusion:}

This research highlights the importance of data mining for telecom operators, it also suggests that data mining should be updated automatically each time a new update was made to the database, i.e., as there is OLAP we must have OLDM . This research suggested that telecom operators have to concentrate more on their e-shopping and e-payment as it is more cost effective, to link its queuing system to its CRM databases and use data from shops for marketing issues. This research proposed a ranking formula for point of sales, and how to figure up selling, deep selling, cross selling, figuring best targeted areas for new service or awareness campaigns, and churn prediction.

\section{Future Work:}

Many of the assumptions made in this study need to be validated using surveys or questionnaires, like reasons for no shown, reasons for not visiting a shop, preference to using VoIP applications to make voice calls, and preferred payment method for both customer and companies. This research recommends that ranking formula should be applied on live database.

\section{REFERENCES}

[1] Internet article. Sep 2012. How to use location-based information to maximize direct marketing campaigns. Available online at: http://dmtiblog.blogspot.com/2012_09_01_archive.html

[2] Reza Hosseini, (2013). “Analysis Of CRM Perspectives Toward Successful Implementation Model”. Life Science Journal;10(2) (ISSN:1097-8135)

[3] V. Umayaparvathi, and Dr. K. Iyakutti (2011). "A Fraud Detection Approach in Telecommunication using Cluster GA" MKU, International Journal of Computer Trends and Technology- May to June Issue 2011, ISSN: 2231-2803

[4] Gary M. Weiss (2005). "Data Mining in Telecommunications". In O. Maimon and L. Rokach (eds.), Data Mining and Knowledge Discovery Handbook: A Complete Guide for Practitioners and Researchers, Kluwer Academic Publishers, 1189-1201

[5] Efraim Turban, Ramesh Sharda and Dursun Delen (2011) "Decision Support and Business Intelligence" 9th Edition Prentice Hall. ISBN-10: 013610729X I ISBN-13: 978-0136107293

[6] D. Ćamilović, (2008). Data Mining and CRM in Telecommunications". Serbian Journal of Management 3 (1) PP. 61 - 72

[7] Rahul J. Jadhav, and Usharani T. Pawar (2011). "Churn Prediction in Telecommunication Using Data Mining Technology" (IJACSA) International Journal of Advanced Computer Science and Applications, Vol. 2, No.2, PP 17-19. 
International Journal of Database Management Systems ( IJDMS ) Vol.6, No.3, June 2014

[8] Shan Jin, Yun Meng, Chunfen Fan, Feng Peng, and Qingzhang Chen (2012). "The Research on Applying Data Mining to Telecom Churn Management" 2nd International Conference on Materials, Mechatronics and Automation Lecture Notes in Information Technology, Vol.15

[9] Krishna Kumar Balaraman, (OCTOBER 22, 2011)"Application of Data Mining in the Telecommunication Industry", Term Paper, Indian Institute of Management Bangalore,

[10] LexisNexis® Market Intelligence, Step-By-Step Instructional Guide. Available at: http://www.lexisnexis.com/literature/pdfs/lc00416-1.pdf

[11] V. Umayaparvathi and K. Iyakutti (March 2012). Applications of Data Mining Techniques in Telecom Churn Prediction". International Journal of Computer Applications (0975 - 8887) Volume 42- No.20.

[12] Diego Calvanese, Luigi Dragone, Daniele Nardi, Riccardo Rosati and Stefano M. Trisolini. (March 2006). "Enterprise Modeling and Data Warehousing in Telecom Italia". Journal Information Systems. Volume 31 Issue 1, March 2006. PP 1-32, doi:10.1016/j.is.2004.07.002

[13] F.H. Chandio, H.A. Nizam ANI, Q.U. A. Nizam ANI, S. Vighio, and M.S. Chandio (2012). "A Comparative Analysis of Various Information Systems Acceptance Models", Sindh Univ. Research Journal. (Sci. Ser.) Vol.44 (2), PP 329-332

[14] Davis, F., and V. Venkatesh, (1996). A critical assessment of potential measurement biases in the technology acceptance model: Three experiments. Int. J Human Comp. Studies, (45). PP 19-45.

[15] Chakravorti S. (2006), "CRM a Content Analysis of Issues and Best Practices", Journal of Consumer Marketing Vol. No 20 PP 385-398.

[16] Copulinsky, J.R. and Wolf, M.J., July-August 1990 Relationship Marketing: Positioning for the Future, Journal of Business Strategy, Vol. 11, PP. 16-20.

[17] Abbas Keramati, Hamed Mehrabi, Navid Mojir (2010). A process-oriented perspective on customer relationship management and organizational performance: An empirical investigation. Industrial Marketing Management PP. 1170-1185

[18] A. Lehmann, W. Fuhrmann, U. Trick, and B. Ghita (2009). A New Approach to Classify and Describe Telecommunication Services. Proceedings of the Fifth Collaborative Research Symposium on Security, E-learning, Internet and Networking (SEIN 2009), Darmstadt, Germany, ISBN: 978-184102-236-9, pp173-182. Available at: http://www.etechnik.org/aufsaetze_vortraege/aufsaetze/lehmann_fuhrmann_trick_ghita_sein2009_p2 p.pdf

[19] Gabriel Macia-Fernandez, Pedro Garcia-Teodoro, and Jesus Diaz-Verdejo (2009). "Fraud in Roaming Scenarios: An overview.” IEEE Wireless Communications (Volume:16, Issue:6) ISSN : 1536-1284. PP.88 - 94

[20] Nick Wood (Dec 2013). Operators need m-commerce reality check. Total Telecom magazine. Available online at:

http://www.totaltele.com/view.aspx?ID=484589\&mail=1159\&C=0\&goback=\%2Egde_23013_memb er_5813350788428234753\#\%21

[21] ITU-T Recommendation I.211 (1993). "B-ISDN Service aspects". Available online at: http://www.itu.int/rec/T-REC-I.211-199303-I/en

[22] ETSI TS 122.101 V9.12.0 (2013). Universal Mobile Telecommunications System (UMTS); Service aspects; Service principles", ETSI. Available online at: http://www.etsi.org/deliver/etsi_ts/122100_122199/122101/09.12.00_60/ts_122101v091200p.pdf

[23] ETSI TS 122.105 V9.1.0 (2010). Universal Mobile Telecommunications System (UMTS); Services and service capabilities. ETSI. Available online at: http://www.etsi.org/deliver/etsi_ts/122100_122199/122105/09.01.00_60/ts_122105v090100p.pdf 